\title{
Risks Faced and Mitigation Strategies Employed By Small and Medium Enterprises in Nairobi, Kenya
}

\author{
Githii Stephen Kagwathi ${ }^{1}$, John Njau Kamau ${ }^{2,} \&$ Mary Muthoni Njau ${ }^{3}$ Stephen \\ Maina Kamau ${ }^{4}$ \\ Department of Business administration, Africa Nazarene University \\ Department of Business Administration, Africa Nazarene University \\ PhD Student, University of Nairobi \\ Nett Consultants, Nairobi
}

\begin{abstract}
The role Small and Medium Enterprises (SMEs) play in an economy cannot be over emphasized in both developed and developing countries and so their existence and survival is a concern not only to the governments but to scholars as well. In Kenya SMEs constitute a very important sector of economy employing majority of citizens. Majority of SMEs started die the same year due to risks, they face among other factors. This study identified capital market, customer relations, operational-economic, global view, and branding risks among others while main risk mitigation strategies were diversification, collaboration, insurance, and use of credits scorecards whereby $66 \%$ of SMEs used at least one of these strategies.
\end{abstract}

Key word: Risks, Risk mitigation, and SMEs

\section{Introduction And Background}

SMEs play a key role in development of any economy (Ariyo, 2005; Luper and Kwanum, 2012) and they are especially important in developing countries like Kenya where poverty eradication and unemployment are still major issues facing citizens. In many countries SMEs account for a higher proportion of all enterprises, for example, in Singapore SMEs make up 99\% of all enterprises and employ seven out of every ten employees (The Business Times, 2012). These statistics are close to South Africa where Rwigema and Karugu (1999) as cited by Smit and Watkins (2012) noted that $90 \%$ of all formal businesses are small, medium or micro enterprises. SMEs constitute a very important sector of Kenyan economy employing many skilled and unskilled Kenyans (KRA, 200). These sentiments were supported by Smit and Watkins (2012) when they cited that the role that SMEs play has been recognized in countries such as Kenya, Malawi, Uganda, Ghana, Burkina Faso, and Nigeria Among others. However, these Small and Medium Enterprises (SMEs) operate in the same environment as large enterprises, but without the associated benefits of adequate capital and human resources of large firms.

In their operations SMEs face many risks such as political, credit, natural disaster and operation risks (Greuning et al 2003). SMEs are not only the most dynamic but are also prone to serious external risks. The SMEs ability to withstand these risks is lesser than that of the larger firms (Virdi, 2005). However some methods have been identified as being used by some SMEs that include diversification, collaboration, insurance and use of credits scorecards. Although several studies have been done regarding SMEs risk management (The Business Times, 2012; Smit and Watkins, 2012 and; Kirytopoulos and Malandrakis, 2006), this field of study is still sketchy especially in Kenya. It is this back drop that has informed this research.

This study is divided sections 1) Definition of Small and Medium Enterprises 2) Importance of Small and Medium Enterprises to the Economy 3) Definition of risk in SMEs 4) Risk Mitigation Strategies 5) Theoretical framework 6) Statement of the problem 7) Data analysis 8) Discussion, conclusion, and recommendations

\section{Definition of Small and Medium Enterprises}

There is no universally accepted definition of small and medium enterprises (SMEs). Leopoulos (2006) as cited by Smit and Watkins (2012) noted that the definition may be influenced by country specific legislation as well as the geographical placement of SMEs. According to Kenya Revenue Authority (2007), a business enterprise that employs between 10-49 and 50-99 people is considered as Small and Medium Enterprise respectively. Further, KRA (2007) noted that Small and Medium manufacturing enterprises in Kenya's manufacturing sector are defined as enterprises with fulltime employees not exceeding 100 or annual sales turnover not exceeding Ksh 150 million. Similarly, Jordan, Lowe and Taylor (1998) define Small or Medium sized firms as firms with less than 100 employees. 
For the purposes of this study KRA (2007) definition was adopted and therefore a small and medium enterprise is an enterprise that employs between 10-49 and 50-99 respectively.

\section{Importance of Small and Medium Enterprises to the Economy}

SMEs throughout the world play an important role in the process of industrialization, economic growth and sustainable development of any economy (Ariyo, 2005). Raghavan (2005) noted that SMEs sectors are mostly sole proprietorship and partnership, which is also evident in the Kenyan economy. According to Rogerson (2001) the activities of SMEs enterprises in Africa are vital for the promotion of economic growth, job creation, and mitigation of poverty. According to Luper and Kwanum (2012), SMEs are important to the development of any economy, as they possess great potentials for employment generation, improvement of local technology, output diversification, development of indigenous entrepreneurship, and forward integration with large-scale industries. As noted earlier, SMEs constitute 99 per cent of all enterprise in Singapore, 95 per cent to 99 per cent of enterprise in Organization for Economic Co-operation and Development (OECD) countries. In South Africa the rate is equally high with 90 per cent being SMEs contributing 80 per cent of employment in the country.

According to KRA (2007), the fundamental contributions of SMEs in Kenya include increased output of goods and services and development of a pool of skilled and semi skilled labor force, which is expected to be a base for future industrial growth. They have also strengthened both forward and backward linkages among socially, economically and geographically diverse sectors of the economy thereby increasing participation of indigenous Kenyans in economic activities of the country. Further they have also created opportunities to cultivate and nurture entrepreneurial and managerial skills of the country. Azende (2012) has noted that SMEs may look small or inconsequential but are actually the foundation of any economically stable nation. Kenya Vision 2030 has recognized the role of SMEs in making Kenya a globally competitive and prosperous nation with high quality of life by 2030. One of the flagship projects for manufacturing/flagship projects for 2012 was to create at least 5 small and medium enterprises industrial parks in the country.

\section{Definition and classification of risks}

According to Raghavan (2005) risk is the potentiality that expected events may have an adverse impact on the capital earnings. Risk could also refer to the chance that some unfavorable event will occur and in this respect risk describes a situation where there is not just one possible outcome of returns to an investment but an array of potential returns. Risk could therefore be viewed as uncertainty of financial loss. According to Markowitz (1952) risk can be classified into either unsystematic or systematic. Systematic risks stems from market factors that affect most firms, such as inflation, recessions and high interest rates which are undiversifiable or systematic in nature. It refers to that portion of total variability in return that is caused by factors affecting the prices of all securities. Unsystematic risk also called diversifiable risk is that related to events that are unique to the firm such as lawsuit, strikes, successful and unsuccessful marketing programs, winning or losing a major contract etc. Alquier and Tignol (2006) suggested that risk could be further classified as endogenous risks (those that are originating from the situation itself) and exogenous risks (those coming from the outside). Greuning et al., (2003), took a different direction in classifying risks as market risk, financial risk, operational risk, business risks, and event risks. Notwithstanding this conflict in classification, what should not be lost is the fact that classifications of risks indicate only the source and not the nature and as such it is not enough in itself. Thus SMEs risks can be summarized broadly into four categories some of which are controllable if suitable actions are taken to do so, while others are largely unpredictable and uncontrollable. Some unpredictable and uncontrollable risks may include fire, floods, earthquakes, political crises and war among many others.

Due to ineffective management in the SMEs sector, the risk that affect them stems from both the market related risk as well as business or operation risks. A study done by Smit and Watkins (2012) found out that few SMEs owners and managers are risk aware and they focus their risk actions on loss control programs in the areas of fire, safety, health and quality assurance. The ability of the management of SMEs to carefully identify the risks that their business could face and take actions accordingly to counter them will certainly lead to successful and profitable ventures and contribute to economic growth of the nation. Smit and Watkins (2012) argued that determining the components of total risk in SMEs is difficult due to the fact that they are heterogeneous and also the difficulty in separating the owner from the business. However, managers that do not take risk management seriously are faced with the problem of performance that threatens the continuous existence of their business which can be equated to what is called risk.

\section{Risk Mitigation Strategies}

Risk and risk mitigation is a major concern for all companies, especially small and medium sized enterprises which are particularly sensitive to business risk and competition (Alquier and Lagasse, 2006). Small to medium businesses are exposed to risks all the time and such risks can directly affect day-to-day operations, 
decrease revenue or increase expenses, an impact that may be serious enough for the business to fail. Risk management function in SMES usually resides with the owner's assessment of threats and opportunities pertaining to the enterprise (Watt, 2007). Ntlhane (1995) asserts that risk management is the core principle that entrepreneurial or management should focus on in recognizing future uncertainty, deliberating risks, possible manifestations and effects, and formulating plans to address these risks and reduce or eliminate its impact on the enterprise. Incorporating risk management into SMEs operations makes them better equipped to exploit their resources and enable organizations to transform an expenditure activity into an activity that can yield a positive return (Kirytopoulos et al., 2001; Banham, 2004).

Risk mitigation is therefore taking prominence even far above issues of financing constraints in longterm as well as short term investments (Plourd, 2009). This field is a rapidly developing discipline and there are many and varied views and descriptions of what risk mitigation involves, how it should be conducted and what it is for. Risk management according to Raghavan (2005) is an ongoing process targeted to enhance operation, practices, resource allocation, ensure compliances to established rules, achieve performance goals, improve financial health and prevent damage to the firm. In general the strategies employed include transferring the risk to another party, avoiding the risk, reducing the negative effect of the risk, and accepting some or all of the consequences of a particular risk.

Traditional risk mitigation focuses on risks stemming from physical or legal causes such as natural disasters or fires, accidents, death, and lawsuits (Feridun, 2006). Risk mitigation is an action in present for securing the future, proactive activity (Raghavan, 2005). It is the process of measuring, or assessing risk and then developing strategies to manage the risk (figure 1)

Ntlhane (1995) found out that SME owner and managers were not versed in the availability and use of risk reduction techniques to reduce the adverse effects of risks on the enterprise. Their study concluded that owners and managers preferred avoiding risks rather than devising risk control methods a conclusion that Smit and Watkins (2012) also came up with. This impedes on the economic progress of a country as every business can be defined by its ability to take on greater risks.

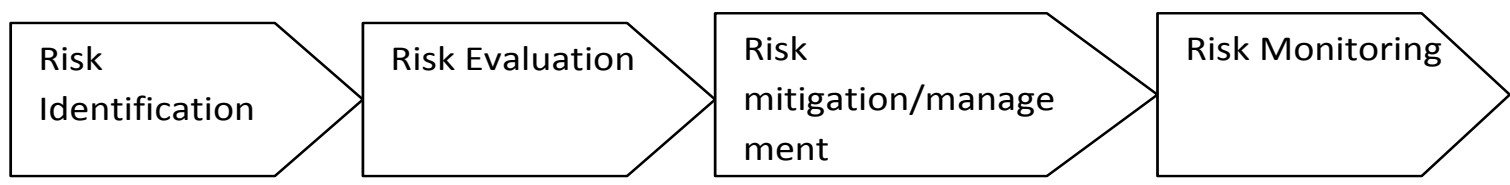

Figure 1 Risk management process

Source: Adapted from Smit (2012)

However, some risk mitigating strategies have been cited in the literature that includes credit scorecard, collaboration, diversification and insurance.

Credit Scorecard: Most economic activities in many countries come from the SMEs sector (Wendel and Harvey, 2006). Yet in many developing countries, SMEs have limited access to formal credit. In sub-Saharan Africa, for example, banking-sector penetration is roughly one percent of the population (Stein, 2001). In Kenya, there are about 2.2 million micro, small and medium enterprises of which 88 percent are non-registered. Of this non-registered group, only 23 percent have bank accounts, and only 10 percent have ever received credit from any formal source (Strategic Business Advisors Africa Ltd 2007).

Fewer than 20 percent of small to medium sized enterprises (SMEs) in Kenya have received credit from formal financial institutions due to challenges in assessing SME risk in a cost effective manner. Lenders in Kenya address this risk-assessment problem either by not lending to SMEs at all or by requiring collateral and charging high interest rates. Lack of cost effective ways to quantify credit risk is one major problems Kenyan lenders are reluctant to lend to SMEs. Steadman Group Research Division (2007) report that there is a common perception that borrowing from formal lenders will lead to loss of assets and property.

Credit scorecards are however available tools used to predict the behavior of new applicants of credit facilities based on previous the performance of applicants (U.S. Comptroller of the Currency, 1998). Scorecards can also be used to predict the performance of existing accounts, based on past experience of accounts with similar characteristics. One major benefit of this strategy is the ability to quantify risk which permits precise targeting of portfolio approval rates, loss rates, and pricing which help lenders compensate for the risk taken. It focuses on the business, the portfolio, and the income statement of the loan portfolio that facilitates understanding the business, processes and policy and also analytics on how to use scorecards to achieve desired results. Scorecards can also be used to predict the performance of existing accounts, based on past experience of accounts with similar characteristics.

The scorecards are of two basic types, judgmental and statistical. Judgmental also known as expertbased scorecards are a set of formal, quantitative criteria developed by incorporating the best practices and the knowledge of senior credit officers. They are useful for standardizing, simplifying, and speeding up decision- 
making. Statistical scorecards are built with data from actual loans and applications, and they have the important added benefit of quantifying the probability of default. Among statistical models there generic scorecards that are built with data from a variety of lenders and performance reported to a centralized repository such as a credit bureau and custom scored cards built with the performance data from a specific financial institution (Microfinance Risk Management, L.L.C 2008).

Credit scoring has the potential to offer a number of benefits which can improve access to credit for SMEs and there is increasing demand for the benefits of scoring among SME lenders. This tool can be very appropriate in reducing credit risks among SMEs since it provides access to formal credit that matches the risk and performance of the enterprise. Appropriate frameworks and property rights can increase lenders willingness to lend (Malhotra et al., 2006) as well as improve the integrity of data used in underwriting and credit scoring and this would facilitate access to finance by smes.

However, there are a number of prerequisites that must be in place in order to fully realize the potential benefits of an effective risk management strategy that incorporates credit scoring. It is also argued that credit scoring models are like antibiotics such that when used appropriately, they bring much benefit, but if not used and managed correctly, they may do more harm than good. Some potential disadvantages resulting from improperly developed, implemented, or managed scorecards (Microfinance Risk Management, L.L.C 2008).

Collaboration: Collaboration could be used to overcome risks in carrying out the operations in the SMEs. It involves linking and joint operation of the different SMEs in Kenya to achieve a better and bigger effort in marketing their products. It promotes technological development, advanced skill and competition among SMEs. The networking or linking brings together SMEs dealing with different products to direct customer supplier links reducing middle men exploitation (Fafchaps, 2004; Pedersen, 2001) and hence reducing cost and risk.

Diversification: Diversification involves running of more than one business as a strategy for risk management by SMEs. This approach is based on the saying that one should not put all eggs in one basket. To some extent SMEs use diversification but the problem has been the process of diversification (Carter, 2003). A study by Njau (2010) reported that many SMEs owners run more than one business as a diversification strategy to manage risk but that the process could be improved if SMEs managers were skilled the choice of suitable business combinations in their portfolios. Alquier and Tignol (2012), agrees with this approach as a more appropriate framework to capture and manage the diversity of risk while maintaining maximum returns.

Insurance: Insurance is another method used by SMEs to manage risks. This involves transferring risk to an insurance company so that in the event that the risk occurs then the insurance firm will take business to its initial state. In developing countries like Kenya insurance is not an obvious choice or alternatives to many SMEs. Smit and Watkin (2012) however, pointed out that in South African there are a small proportion of owners who use insurance as a risk management technique. Premierline Direct noted that SMEs have difficulty understanding business insurance and what risks their policy covers them against. The research also highlighted that the lack of knowledge about insurance is disturbing and it appears business people under-value insurance.

Risk management is less well developed within smaller entities where the strong enterprise culture mitigates against managing risks in a professional structured way. This attitude persists despite evidence that businesses that adopt risk management strategies are more likely to survive and grow (Virdi 2005). According to the ICAEW's policy document on entrepreneurship (2005) SMEs place too little emphasis on risk management.

\section{Theoretical Review}

This study was premised on the theory of opportunistic entrepreneurship, portfolio theory and capital asset pricing model.

The Theory of Opportunistic Entrepreneurship: Cressy (1991) on the theory of entrepreneurial opportunism points out that the theory allows the individual to receive a continuous sequence of projects in each of which he makes a decision to invest or not. The model takes the form of the derivation of an optimal decision rule over project success based on probability which maximizes the entrepreneur's expected return and minimize risk given his current knowledge. This rule tells the entrepreneur which projects to accept and which to reject. The optimal reservation probability is shown to be a function of the quality of the entrepreneur's data, ability to formulate the correct model and to update that model as information accumulates.

Portfolio Theory: The basis of portfolio theory was first developed in 1959 by Harry Markowitz. The common sense behind the portfolio theory is based on the adage 'do not put all your eggs in one basket'. This explains the risk- reducing effect of spreading investment across a range of assets, that in a portfolio unexpected bad news concerning one company will be compensated for to some extent by an expected good news about another. Markowitz (1959) has given the tools for identifying portfolios which give the highest return for a particular level of risk. The investors can then select the optimum risk-return trade-off for themselves depending on the of personal risk aversion. These portfolios of different proportions satisfy a particular level of investor risk 
tolerance. According to the portfolio theory there is a risk- reducing effect of spreading investment across a range of assets rather than running a single investment.

Capital asset pricing model and arbitrage pricing theory: Financial theory posits that the only relevant risk of an asset should be its level of systematic risk, as this risk cannot be diversified away. The cost of capital is a linear function of systematic risk (Ross et al 2005). The asset pricing theory uses one systematic risk factor as the market risk, while the capital asset pricing model an asset's exposure to market risk is measured by its beta (Roll 1977). In both theories expected return is a trade off with risk. Different approaches are used to measure risk and they provide a rational framework for decision making provided existing information relevant to an event is fully appraised and deductions are based solely on such information (Fama et al 1992, 1996, 2004).

\section{Statement of the problem}

In a number of developing countries, a substantial number of new job seekers, retrenched workers, and even pensioners, have turned to SMEs as a source of livelihood. A study on contribution of SMEs on employment growth in Southern and Eastern Africa, indicated that SMEs have absorbed close to a third of the total increase in population of working age (15 - 64) and over $40 \%$ of the total increase in the labor-force since 1980s (Selejio et al, 2005). The National Baseline Survey, 1999 revealed existence of some 1.3 million SMEs employing as many as 2.4 million Kenyans (CBS/ICEG/K-REP 1999). Another study by Kimuyu (1999) has shown that the sector is very dynamic, as evidenced by the rapid rate of investment and enterprise growth. The development of the sector is therefore critical in reducing poverty in Kenya.

Though SMEs are very important to the growth of economies, research conducted on SMEs in Africa by Mead and Liedholm (1998) found out that on average there are more SMEs closures than expansions, with only approximately $1 \%$ of micro enterprises growing from five or less employees to ten or more. According to Torres et al (1993), 58\% of SMEs started in Kenya hardly grow to become medium or large enterprises; they remain static, while $4 \%$ die at an early stage. This implies that more than half of SMEs started do not achieve their intended goal. While the survey identified access to credit as the principal course of the trend, more than 150 credit schemes NBS (1999) had been established to reverse the situation but in the same year (1999) over11360 SMEs were closed. A survey conducted in Kenya, Nairobi by Bowel et al (2009) reported that the main challenges facing SMEs are competition, insecurity, debt collection, and lack of working capital and power interruptions. Political uncertainty, cost of materials, low demand and restrictive by-laws completed the list of main challenges facing these businesses.

According to Smit and Watkins (2012), failure of SMEs can be attributed to lack of management skills. Risk management is one of such skills. A study by Luper and Kwanum (2012) in Nigeria found out that $84 \%$ of SMEs did not cover their business against risks. Another Study done for ICEAW by Virdi (2005) reported that about half of SMEs have no risk management procedures in place and about a fifth of larger businesses also do not, suggesting that risk management is not totally embedded even among large businesses. The study also found out that while typically 50-60\% of businesses claim to have formal risk management procedures in place, ranging from identifying risks to reporting back on risks, there are significant differences by business size. According to this research, the annual spending on risk management varies considerably by size of business, with smaller businesses spending on average considerably less than larger businesses. In the same study a report on the attitude to risk indicated that vast majority of businesses $(86 \%)$ do not believe that adequate insurance for major risks precludes the necessity of regularly raising the issue of risks. Although there is a slightly greater inclination towards insurance among small businesses, there is a need for additional risk management strategies across the board.

The ability of the management of SMEs to carefully identify the risks that their business could face and take actions accordingly to counter them will certainly lead to successful and profitable ventures and contribute to economic growth of the nation. By incorporating risk management into SMEs operations, SMEs are better equipped to exploit their resources, thereby enabling their organizations to transform an expenditure activity into an activity that can yield a positive return (Kirytopoulos et al., 2001; Banham, 2004). The purpose of this study was to identify types of risk faced by these SMEs and the extent to which they employ risk mitigation strategies to improve performance and consequently growth in Kenya.

\section{Objective of the study}

The objectives of this study was to identify various types of risks faced by SMEs and to determine the extent to which the SMEs employ diversification, collaboration, credit scorecard and insurance as risk mitigation strategies towards performance and growth. The study had hypothesized that there was no a significance difference in the level of adoption of the different risk mitigation strategies by SMEs.

\section{Methodology}


The target population of the study was small and medium enterprises in Nairobi and its environs. The study avoided micro enterprises, as they were considered inappropriate for a study involving technical aspects of management. The study adopted descriptive design and due to the technicalities involved in gathering of the data and homogeneity of SMEs operations a relatively small sample of 100 enterprises were served with questionnaires but actually only 62 questionnaires were returned representing $62 \%$ response rate. This response rate was a bit lower than expected but still good enough for intended analysis. The main business targeted were general retail shops, cosmetic and beauty shops, money transfer businesses (Mpesa), transport, private school, restaurants, and agribusinesses among others. This was considered fairly good as the served questionnaires demanded a time and careful considerations in filling them. The study was also cross sectional as it was done between May and June 2013. The questionnaire was divided into three sections: background, types of risk faced by SMES and risk mitigation strategies. Data was then analyzed through factor analysis, chi-square, and MANOVA using SPSS version 17.

\section{Data Analysis}

This section contains analysis divided into three main sub-sections. Section one is the background information, section two factor analysis on the type of risks and section three on the risk mitigation strategies.

\section{Background analysis}

The study found out that $37 \%$ of businesses had been in existence for less than three years. This indicates that they were relatively new and therefore may not have applied most of the risk mitigation strategies. Closer examination of the findings showed $71 \%$ of enterprises had been in existence for less than six years. This may explain why majority of SMEs may not have embraced most of risk mitigation strategies like diversification, as they were still in the formation stage. Only $11 \%$ had been in existence for over ten years and could be applying most of the mitigation strategies. Analysis on the number of employees revealed that most of the enterprises fit in the category of small enterprises, which employ up to five people while only $13 \%$ qualify as medium enterprises. Analysis on the initial capital employed indicated that majority of enterprises (32\%) had an initial starting capital of between 1000 to 5000 USD. Only 3\% of enterprises had less than 50 USD as the starting capital while 9\% had more than half 5000 USD as their starting capital. Further analysis on source of initial capital showed that $61 \%$ sourced the money from their personal savings, $21 \%$ from family and friends while only $12 \%$ sourced their capital from financial institutions. This clearly indicates that access to credit facilities remain a big challenge among small and medium enterprises in developing countries especially from financial institutions. This analyzes clearly support the KRA (2007) definition of SMEs in Kenya.

\section{Factor analysis}

To identify the various types of risk faced by SMEs, factor analysis was conducted to include appropriateness of the model, communalities, total variance explained, and the factors extracted from the process. To test the appropriateness of the factor analysis model used in identifying risks faced by the enterprises, Bartlett's test of sphericity was used to test the null hypothesis that the variables were uncorrelated. The results of PCA demonstrated that the null hypothesis, (that the risks correlation matrix was an identity matrix) was rejected by the Bartlett's test of sphericity table 1 . The approximate chi-square statistics was 1229.976 with 1035 degrees of freedom, which was significant at the 0.05 level. The values of KMO statistic (.448) is just slightly less than 0.5 . Thus, factor analysis was considered an appropriate technique for analyzing the correlation matrix. Using principal component analysis (PCA) to extract communalities among the variables, the result indicates that all factors accounted for a significant proportion of variance as they range from 0.631 to 0.853 .

\begin{tabular}{|l|l|l|}
\hline \multicolumn{2}{|l|}{ Kaiser-Meyer-Olkin Measure of Sampling Adequacy } & .448 \\
\hline Bartlett's Test of Sphericity & Approx. Chi-Square & 1229.976 \\
\cline { 2 - 3 } & df & 1035 \\
\cline { 2 - 3 } & Sig. & .000 \\
\hline
\end{tabular}

\section{Table:1 KMO and Bartlett's Test}

We conducted factor analysis on 62 questionnaire sent to participants of the study. Using Eigen values greater than 1.0, total explained variance, and factor loadings greater than 0.45 as criteria for identifying meaningful risks (see Nunnally and Bernstein, 1994), we identified 15 types of risks (or categories). The Scree plot also supported the extraction of the fifteen different types of risks. The rotated factor matrix sorted out 15 factors that were deemed significant for this study. Each of the factor had loadings greater than 0.45 . The rotation method used was Varimax with Kaiser Normalization where items were sorted from one with the highest loading to the one with lowest. The results of the rotated matrix helped to identify the major risks faced by entrepreneurs in this sector. The study had forty-six initial variables, which were reduced to fifteen factors. They account for $77 \%$ of variance with loadings ranging between 0.452 to 0.846 . The identified factors are presented in the Table 2. 


\begin{tabular}{|c|c|c|c|c|}
\hline Variable & Description of the variable & $\begin{array}{l}\text { Factor } \\
\text { loadings }\end{array}$ & $\begin{array}{c}\text { Explained\% } \\
\text { Variance }\end{array}$ & Factor \\
\hline VAR00028 & $\begin{array}{l}\text { Limited ways of raising funds prevent expansion of business } \\
\text { operations }\end{array}$ & .812 & \multirow[t]{4}{*}{6.824} & \multirow[t]{4}{*}{$\begin{array}{l}\text { Capital market } \\
\text { risks }\end{array}$} \\
\hline VAR00026 & $\begin{array}{l}\text { Exchange rates fluctuation greatly affects importation and export } \\
\text { in my business }\end{array}$ & .701 & & \\
\hline VAR00023 & $\begin{array}{l}\text { High interest on loans have greatly hindered access of additional } \\
\text { capital to my business }\end{array}$ & .700 & & \\
\hline VAR00025 & Collaterals demanded by banks are not readily available & .532 & & \\
\hline VAR00016 & Theft by employees and customers is a common problem & .820 & \multirow[t]{5}{*}{6.066} & \multirow{5}{*}{$\begin{array}{l}\text { Operational- } \\
\text { economic risk }\end{array}$} \\
\hline VAR00015 & Frequent price fluctuations affects sales volume greatly & .669 & & \\
\hline VAR00005 & Lack of full commitment to duty by employees is a big problem & .647 & & \\
\hline VAR00027 & High inflation levels greatly reduces my profit margin & .583 & & \\
\hline VAR00045 & $\begin{array}{l}\text { Low economic growth in Kenya has negatively affected my } \\
\text { business }\end{array}$ & .452 & & \\
\hline VAR00008 & $\begin{array}{l}\text { Lack of technological expertise by management results in loss of } \\
\text { profit }\end{array}$ & .773 & \multirow[t]{5}{*}{5.834} & \multirow[t]{5}{*}{$\begin{array}{c}\text { Customer relations } \\
\text { risks }\end{array}$} \\
\hline VAR00010 & Customer retention is a major concern to my business & .620 & & \\
\hline VAR00044 & $\begin{array}{l}\text { Lack of product variety limits the number and types of customer } \\
\text { to my business }\end{array}$ & .554 & & \\
\hline VAR00043 & $\begin{array}{l}\text { Hawking around the premises greatly reduces number of } \\
\text { customers to my business }\end{array}$ & .542 & & \\
\hline VAR00029 & $\begin{array}{l}\text { Debt collection from my customers is a big problem in my } \\
\text { business }\end{array}$ & .458 & & \\
\hline VAR00039 & $\begin{array}{l}\text { Access to global markets through internet by my customers has } \\
\text { greatly reduced demand for my goods }\end{array}$ & .798 & \multirow[t]{2}{*}{5.624} & \multirow[t]{2}{*}{ Global-view Risks } \\
\hline VAR00040 & $\begin{array}{l}\text { My lack of exposure to global markets hinder expansion of my } \\
\text { business }\end{array}$ & .724 & & \\
\hline VAR00030 & Registration fee for my business is a great cost & .793 & \multirow[t]{3}{*}{5.612} & \multirow{3}{*}{$\begin{array}{l}\text { Regulatory \& } \\
\text { Compliance risk }\end{array}$} \\
\hline VAR00031 & Annual license renewal is very expensive & .769 & & \\
\hline VAR00032 & Maintaining set standard by regulating agencies is difficult & .528 & & \\
\hline VAR00034 & Big firms take most of my potential customers & .687 & \multirow[t]{3}{*}{5.350} & \multirow[t]{3}{*}{ Branding risks } \\
\hline VAR00035 & $\begin{array}{l}\text { Too much money is spent on attracting and maintaining } \\
\text { customers }\end{array}$ & .641 & & \\
\hline VAR00013 & Building a good name for my business is a big challenge & .627 & & \\
\hline VAR00011 & Promotion cost are very high in my business & .725 & \multirow[t]{3}{*}{5.099} & \multirow[t]{3}{*}{ Inventory Risk } \\
\hline VAR00014 & On time delivery of goods is a big challenge & .711 & & \\
\hline VAR00012 & Suppliers of goods to my business are very unreliable & .577 & & \\
\hline VAR00006 & Technology used in your business gets outdated very first & .716 & \multirow[t]{3}{*}{4.941} & \multirow[t]{3}{*}{ Continuity Risk } \\
\hline VAR00046 & $\begin{array}{l}\text { Past failure in business reduces confidence to try again in the } \\
\text { same area }\end{array}$ & .642 & & \\
\hline VAR00003 & $\begin{array}{l}\text { Loss due to death of your trained employee pauses a big } \\
\text { challenge }\end{array}$ & .563 & & \\
\hline VAR00021 & $\begin{array}{l}\text { Natural disasters (earthquakes, draught, floods) have always } \\
\text { affected my business }\end{array}$ & .822 & \multirow[t]{3}{*}{4.866} & \multirow[t]{3}{*}{ Readiness Risk } \\
\hline VAR00022 & $\begin{array}{l}\text { Loss of goods due to accidents on transportation always affect } \\
\text { my business }\end{array}$ & .645 & & \\
\hline VAR00038 & $\begin{array}{l}\text { Availability of alternative goods reduces demand for my goods } \\
\text { greatly }\end{array}$ & .599 & & \\
\hline VAR00018 & Threat of terrorism is very real in my business & .793 & \multirow[t]{2}{*}{4.830} & \multirow[t]{2}{*}{ Intimidation Risk } \\
\hline VAR00024 & $\begin{array}{l}\text { High level of debts from financial institutions prevents further } \\
\text { borrowing }\end{array}$ & .731 & & \\
\hline VAR00004 & $\begin{array}{l}\text { Poaching of your employees by other businesses is a common } \\
\text { trend }\end{array}$ & .846 & \multirow[t]{2}{*}{4.733} & \multirow[t]{2}{*}{$\begin{array}{l}\text { Employees loss } \\
\text { risks }\end{array}$} \\
\hline VAR00009 & Sales turnover is always below projections & .763 & & \\
\hline VAR00001 & Skilled employs are not easily available & .783 & \multirow[t]{3}{*}{4.665} & \multirow{3}{*}{$\begin{array}{l}\text { Technical skills } \\
\text { risks }\end{array}$} \\
\hline VAR00007 & $\begin{array}{l}\text { High cost of installing new technology reduces profitability of } \\
\text { your firm }\end{array}$ & .643 & & \\
\hline VAR00002 & Retention of our own trained employees is difficulty & .467 & & \\
\hline VAR00042 & $\begin{array}{l}\text { Overdependence on the owner pauses termination of business in } \\
\text { his/her absence }\end{array}$ & .716 & \multirow[t]{2}{*}{4.602} & \multirow[t]{2}{*}{ Stability risks } \\
\hline VAR00041 & $\begin{array}{l}\text { Political instability in the country threatens the closure of my } \\
\text { business }\end{array}$ & .675 & & \\
\hline VAR00037 & $\begin{array}{l}\text { Too many competitors always lead to downward trend in prices } \\
\text { of my goods/ services }\end{array}$ & .820 & 4.253 & Competition risks \\
\hline
\end{tabular}




\begin{tabular}{|l|l|l|l|}
\hline VAR00036 & Location of my business is not conducive for my customers & .515 & \\
\hline VAR00020 & Power supply is always interrupted & .870 & \multirow{2}{*}{3.715} \\
\cline { 1 - 2 } VAR0017 & Robbery by violence in the premises is a frequent occurrence & -.526 & \\
\hline
\end{tabular}

\section{Table 2: Explanation of variables (risks)}

\section{Risk mitigation strategies}

The study sought to identify various risk mitigation strategies used by SMEs and determine whether they were used equally and if not which was more popular. The study also assessed the association between the different strategies and different aspects of business growth. The study focused on four risk mitigation strategies namely collaboration, insurance, credit scorecard and diversification.

\begin{tabular}{|c|c|c|c|c|}
\hline \multirow[t]{2}{*}{ Strategies } & & \multicolumn{2}{|c|}{ Adoption } & \multirow[b]{2}{*}{ Total } \\
\hline & & No & Yes & \\
\hline \multirow[t]{4}{*}{ Collaboration } & Count & 43 & 19 & 62 \\
\hline & Expected Count & 41.5 & 20.5 & 62.0 \\
\hline & $\%$ within strategy & $69.4 \%$ & $30.6 \%$ & $100.0 \%$ \\
\hline & $\%$ within status & $25.9 \%$ & $23.2 \%$ & $25.0 \%$ \\
\hline \multirow[t]{4}{*}{ Diversification } & Count & 43 & 19 & 62 \\
\hline & Expected Count & 41.5 & 20.5 & 62.0 \\
\hline & $\%$ within strategy & $69.4 \%$ & $30.6 \%$ & $100.0 \%$ \\
\hline & $\%$ within status & $25.9 \%$ & $23.2 \%$ & $25.0 \%$ \\
\hline \multirow[t]{4}{*}{ Insurance } & Count & 48 & 14 & 62 \\
\hline & Expected Count & 41.5 & 20.5 & 62.0 \\
\hline & $\%$ within strategy & $77.4 \%$ & $22.6 \%$ & $100.0 \%$ \\
\hline & $\%$ within status & $28.9 \%$ & $17.1 \%$ & $25.0 \%$ \\
\hline \multirow[t]{4}{*}{ Scorecard } & Count & 32 & 30 & 62 \\
\hline & Expected Count & 41.5 & 20.5 & 62.0 \\
\hline & $\%$ within strategy & $51.6 \%$ & $48.4 \%$ & $100.0 \%$ \\
\hline & $\%$ within status & $19.3 \%$ & $36.6 \%$ & $25.0 \%$ \\
\hline
\end{tabular}

Table 3: Strategy in use

From the study, we found out that credit scored card was the most popular strategy followed by diversification and collaboration while insurance was the least at as shown in cross tabulation table 3 .

The result on chi-square test $\left(\mathrm{X}^{2}(9.984, \mathrm{~N}=62)=9.984, \mathrm{p}=0.19\right)$ on hypothesis that there was no significance difference in the adoption of the different risk mitigation strategies by SMEs is also shown in table 4. Based on the $p$ value $=0.019$ compared to $(p<0.05)$ we rejected the null hypothesis and concluded that there was a significant difference in adoption of the different risk mitigation strategies by SMEs. The choice of a strategy depended on other available risk mitigation strategies

\begin{tabular}{|l|r|r|r|}
\hline & \multicolumn{1}{|c|}{ Value } & \multicolumn{1}{c|}{ df } & \multicolumn{1}{|c|}{ Asymp. Sig. (2-sided) } \\
\hline Pearson Chi-Square & $9.984^{\mathrm{a}}$ & 3 & .019 \\
\hline Likelihood Ratio & 9.832 & 3 & .020 \\
\hline & & & \\
\hline N of Valid Cases & 248 & & \\
\hline
\end{tabular}

Table 4: Chi-Square Tests

The $\mathrm{p}$ values on the multivariate test are slightly above the p-value of 0.05 as shown in table 5 . This shows that the there is no significance association between the risk mitigation strategies and growth and performance aspects of the enterprises. The study also focused on finding out whether there was any association between the risk mitigation strategies and the performance and growth of the enterprises. The factors used to operationalize the aspects of performance and growth were increase in profit, number of customers, qualification of employees, application of modern technology and reduction of operation costs.

\begin{tabular}{|c|c|c|c|c|c|c|c|c|}
\hline Effect & & Value & $\mathrm{F}$ & Hypothesis df & Error $\mathrm{df}$ & Sig. & $\begin{array}{l}\text { Noncent. } \\
\text { Parameter }\end{array}$ & $\begin{array}{l}\text { Observed } \\
\text { Power }^{\mathrm{b}}\end{array}$ \\
\hline \multirow[t]{4}{*}{ Intercept } & Pillai's Trace & .932 & $140.873^{\mathrm{a}}$ & 7.000 & 72.000 & .000 & 986.111 & 1.000 \\
\hline & Wilks' Lambda & .068 & $140.873^{\mathrm{a}}$ & 7.000 & 72.000 & .000 & 986.111 & 1.000 \\
\hline & $\begin{array}{l}\text { Hotelling's } \\
\text { Trace }\end{array}$ & 13.696 & $140.873^{\mathrm{a}}$ & 7.000 & 72.000 & .000 & 986.111 & 1.000 \\
\hline & $\begin{array}{l}\text { Roy's Largest } \\
\text { Root }\end{array}$ & 13.696 & $140.873^{\mathrm{a}}$ & 7.000 & 72.000 & .000 & 986.111 & 1.000 \\
\hline \multirow[t]{3}{*}{ VAR00001 } & Pillai's Trace & .390 & 1.581 & 21.000 & 222.000 & .055 & 33.209 & .947 \\
\hline & Wilks' Lambda & .651 & 1.593 & 21.000 & 207.295 & .053 & 31.907 & .935 \\
\hline & Hotelling's & .475 & 1.599 & 21.000 & 212.000 & .052 & 33.569 & .949 \\
\hline
\end{tabular}


Risks Faced And Mitigation Strategies Employed By Small And Medium Enterprises In Nairobi, Kenya

\begin{tabular}{|l|l|r|r|r|r|r|r|r|}
\hline & Trace & & & & & & & \\
\hline & $\begin{array}{l}\text { Roy's Largest } \\
\text { Root }\end{array}$ & .294 & $3.103^{\mathrm{c}}$ & 7.000 & 74.000 & $\mathbf{. 0 0 6}$ & 21.722 & .925 \\
\hline
\end{tabular}

Computed using alpha $=.05$

Table 5: Multivariate Tests

The MANOVA analysis on tests of between-subjects effects for the combined independent variables (risk mitigation strategies) were all insignificant except on the variable on increase of customers, which was significant with p-value equal to 0.007 , which is less than significance level of 0.05 as shown in table 6 .

\begin{tabular}{|c|c|c|c|c|c|c|c|c|}
\hline Source & $\begin{array}{l}\text { Dependent } \\
\text { Variable }\end{array}$ & $\begin{array}{l}\text { Type III Sum } \\
\text { of Squares }\end{array}$ & df & $\begin{array}{l}\text { Mean } \\
\text { Square }\end{array}$ & $\mathrm{F}$ & Sig. & $\begin{array}{l}\text { Noncent. } \\
\text { Parameter }\end{array}$ & $\begin{array}{l}\text { Observed } \\
\text { Power }^{\mathrm{b}}\end{array}$ \\
\hline \multirow{7}{*}{$\begin{array}{l}\text { Corrected } \\
\text { Model }\end{array}$} & profit & $14.228^{\mathrm{a}}$ & 4 & 3.557 & 1.918 & .116 & 7.671 & .555 \\
\hline & technology & $9.283^{\mathrm{c}}$ & 4 & 2.321 & 1.468 & .220 & 5.874 & .436 \\
\hline & customers & $25.799^{\mathrm{d}}$ & 4 & 6.450 & 3.772 & .007 & 15.087 & .872 \\
\hline & Cost reduction & $8.498^{\mathrm{e}}$ & 4 & 2.124 & .978 & .424 & 3.913 & .296 \\
\hline & $\begin{array}{l}\text { Qualified } \\
\text { employee }\end{array}$ & $7.970^{f}$ & 4 & 1.992 & 1.070 & .377 & 4.281 & .322 \\
\hline & $\begin{array}{l}\text { Number of } \\
\text { business }\end{array}$ & $10.526^{\mathrm{g}}$ & 4 & 2.632 & .976 & .425 & 3.905 & .295 \\
\hline & continuity & $6.522^{h}$ & 4 & 1.631 & 1.052 & .386 & 4.206 & .317 \\
\hline
\end{tabular}

a. $\quad$ R Squared $=.090$ (Adjusted R Squared $=.043$ )

b. Computed using alpha $=.05$

Table: 6 Tests of Between-Subjects Effects

\section{Discussion, Conclusion, And Recommendations}

Risk management remains a major challenge to owners and managers of SMEs in developing countries like Kenya. This is because SMEs are faced with many risks that most major enterprises have ways and strategies of managing. The size of the enterprise in terms of amount of capital employed, quality and number of employees and the duration of existence all contribute to increased levels of business risks.

This study identified 15 major categories of risks faced by these enterprises. These categories of risks constituted $77 \%$ of total variance explained through factor analysis. Capital market risk rated as the greatest challenge of SMEs contributed $6.824 \%$ of the total variance explained. This supports the findings of Smit and Watkins (2012). From these findings, it is clear that this type of risk is yet to be addressed by financial institutions and the governments of developing countries. In Kenya for instances NBS 1999 indicated that over 150 financing scheme from both the government and private sector were already established but this has not reduced the capital market risks. Entrepreneurs also rated operational-economic risk quite highly contributing $6.066 \%$ of total variance explained. Unstable economy and unpredictable growth patterns witnessed in these economies heavily affects the SMEs sector. Internal inefficiencies such as theft by employees and lack of commitment also put SMEs at high risk. Internal inefficiency could be attributed to low levels of training of owners and employees as well as low salaries that may result to low motivation of employees.

Customer is still considered the king in many businesses. SMEs face risk in the inability to relate well with their customers which accounted for $5.834 \%$ of the total variance explained. Customer relationship management has become a key emphasis in running successful businesses today, which is achieved through articulate management skills. However, lack of proper training among employees and managers of SMEs could be the main contributor to this behavior. Coupled with this is the market risk (the inability of entrepreneurs to brand their businesses) which accounted for $5.32 \%$ of total variance explained. Major businesses are able to brand themselves making it easier for them to segment and target certain markets such that their customers are able to differentiate their product easily and hence become loyal to firm's product. Lack of this advantage puts SMEs at risk.

Many of these entrepreneurs lack a wide global view of business, their understanding of global trends is wanting, and this accounted for 5.624\% of total variance. This may be explained by their low levels of exposure, ignorance and inability to apply modern technology in their business. The SMEs inability to establish efficient supply system (inventory risk) and unpreparedness to deal with disasters and accidents (readiness risk) accounted for $5.099 \%$ and $4.866 \%$ of total variance explained respectively. This may be attributed to low working capital and traditions of assuming risks. The business environment in Kenya is clogged with rules and regulations posing regulatory, and compliance risks to business owners accounting for $5.612 \%$ of the total variance explained. In Kenya, it takes 21 days to start a business compared with Rwanda where it takes 3 days. This explains this risk and its heavy impact on growth and performance of SMEs. Risk arising from competition was not perceived to be a major risk as it accounted for only $4.532 \%$ together with interruption risks arising from power interruptions, which accounted only for $3.715 \%$ of total variance explained. This is a bit of surprise, 
as it would be expected that competition would pose a major competition risk as this is the trend in modern business world. In addition, robbery by violence received negative loadings meaning it was not considered a major risk among small and medium enterprises. This is contrary to popular opinions that business environment is very unsafe among SMEs. Continuity and stability risks as well as loss of employees are other relatively low risks faced by entrepreneurs.

Risk mitigation strategies among SMEs were a key focus of this study. Among the enterprises that applied at least one risk mitigation strategy, credit scorecard was used by $48 \%$ of enterprises and rated the most popular. Other strategies; diversification, collaboration and insurance had low level of use among the SMEs. These findings therefore support a study by Smit and Watkin (2012) which reported low level of the use of insurance among SMEs in S. Africa. Credit scorecard is a strategy that takes into consideration the level of credit risk an enterprise can handle which is based on the performance evaluated from enterprise's available data. However, demand for availability of data for performance valuation is initiated by the financial institutions and not by the SMEs and so this strategy is only externally enforced. The chi-square analysis also supports the fact that SMEs favor some risk mitigation strategies to others and for different purposes. MANOVA test indicates that most entrepreneurs apply risk mitigation strategies to focus on securing as many customers as possible. Post hoc analysis could not identify one strategy that entrepreneurs deem to have the greatest impact in the performance and growth of their businesses since the multivariate test gave p- value slightly above 0.05 . Apart from securing customers, the other SMEs growth indicators such as profit increase, cost reduction, use of modern technology and increase in number of business units, there was no specific risk mitigation strategy that had a positive impact on all of the indicators. To achieve effective risk mitigation among SMEs a combination of strategies would be recommended as the way forward.

We conclude that risk is a major issue among SMEs in Kenya as over fifteen different categories of risk have been well identified. SMEs favor some risk mitigation strategies over others and so there is need to identify the most appropriate and effective risk mitigation strategies among the SME. More studies should be conducted to determine factors influencing the choice of mitigation strategies. Future studies should also identify why insurance is the least applied strategy among SMES.

\section{References}

[1]. Alila, O.P., \& Pedersen P.O. (Eds). 2001. Negotiating social space: East African Microenterprises. Africa World Press.

[2]. Alquier, B., \& Lagasse, T. 2006. Risk management in small-medium sized enterprises. African Journal of Business Management, 17:273-282.

[3]. Alquier, B.A. 2012. A method for knowledge capitalization driven by the implementation of a strategic decision support system. IPMA '98 World Congress on Project Management. Ljubjana, Slovenia.

[4]. Ariyo, D. 2005. Small firms are the backbone of Nigerian economy, Retrieved September 15, 2013 from www.africaneconomicanalysis.org.

[5]. Azende, T. 2012. Risk management and Insurance of small and medium scale enterprises (SMEs) in Nigeria. International Journal of Finance and Accounting, 1(1), 8-17.

[6]. Business Times. 1997. Training cuts the rate of failure. Online Available at: http://www. btimes.co.za/97/1026/survey/survey17.htm. Accessed: 26 September 2013.

[7]. Carter, D., McNulty, J., \& Verbrugge, J. 2004. Do small banks have an advantage in lending? An examination of risk-adjusted yields on business loans at large and small banks. Journal of Financial Services Research, 25: $233-252$.

[8]. Carter, S. 2003. Reassessing portfolio entrepreneurship. Small Business Economics Journal 21: 371-380

[9]. Donald, M. \& Carl, L. 1998. The dynamics of micro and small enterprises in developing countries, World Development, 26: 61-74

[10]. Fafchamps, M. 2002. Networks, communities and markets in SSA: Implications for firm growth and investment. Journal of African Economies, 10: 109-142.

[11]. Hofmann, M. A. 2009. Interest in enterprise risk management is growing, Business Insurance, 43(18), 14-16.

[12]. Kamau, J., \& Njau, M. 2011. The architecture of a business research project, Nairobi: Salmon Regened Itd

[13]. Leopoulos, V., Kirytopoulos, K., \& Malandrakis, C. 2006. Risk management for SMEs: Tools to use and how. Production Planning \& Control, 17(3), 322-332.

[14]. Luper, I., \& Kwanum, I. M. 2012. Capital structure and firm performance: Evidence from manufacturing companies in Nigeria. Research Journal of Finance and Accounting, 3 (5), 151-158

[15]. Markowitz, H.1959. Portfolio selection: Efficient diversification of investments, New York: Wiley

[16]. Ntlhane, K.E. 1995. The application of risk management principles to smaller enterprises. Unpublished Masters of Business Administration Thesis, University of Witwatersrand, Johannesburg.

[17]. Plourd, K. 2009. Rethinking risk. CFO Magazine. January: 66-69.

[18]. Raghavan, A. M. \& Sayeed. 2005. Achieving coherent capacity of correlated MIMO channels in the low- power regime with nonflashy signaling schemes," in Proceedings of IEEE International Symposium on Information Theory, Adelaide, Australia, pp. 906-910, Sept. 4-9.

[19]. Raghavan, K. M. \&. Prabhu, P. C. \& Sommen, 2004. Analysis of real-Fourier domain based adaptive algorithms implemented with the Hartley transform using cosine-sine symmetries, IEEE Trans. On Signal Processing, 53:622- 629

[20]. Rogerson, C.M., 2001. Growing the SMME Manufacturing Economy of South Africa: Evidence from Gauteng Province. Journal of contemporary African studies 19(2): 267-291.

[21]. Tatsiopoulos, I., Leopoulos, V. \& Kirytopoulos, K. 2001. Risk as a strategic decision factor for the competitive bidding process in contract manufacturing, Proceedings of the IFIP Conference, Aalborg, Denmark, 100-107.

[22]. Watson, G.E.2004. A situational analysis of entrepreneurship mentors in South Africa. University of South Africa.

[23]. Yolande,S. \& Watkins, J.A.2004. A literature review of small and medium enterprises (SME) risk management practices in South Africa. African Journal of Business Management, 6(21): 6324-6330. 
